\title{
Inhibition of Candida albicans growth by steeping freeze-dried robusta ground coffee
}

\author{
Purwanto Purwanto $^{1}$ (D), Yoan Ayung Sagita² ${ }^{\text {(D) }}$, Pujiana Endah Lestari ${ }^{1}$ (D), Depi Praharani ${ }^{3}$ (D), Yahya Jani ${ }^{4}$ (iD), Abubakar Yaro ${ }^{5}$ (iD
}

${ }^{1}$ Jember University, Faculty of Dentistry, Department of Biomedical Science, Jember, Indonesia

${ }^{2}$ Aisyiyah Primary Clinic, Brondong, Lamongan, Indonesia

3.

${ }^{4}$ Linnaeus University, Faculty of Health and Life Sciences, Kalmar, Sweden.

${ }^{5}$ Institute of Health Sciences \& Research, Africa Health Research Organization, Glasgow, Scotland, UK

Contact authors: purwanto@unej.ac.id,yoan.ayung@gmail.com, el_pujiana.fkg@unej.ac.id, praharanidepi.fkg@unej.ac.id, yahya.jani@Inu.se, afhereor@gmail.com

Received in November 11, 2019 and approved in March 10, 2020

\section{ABSTRACT}

Coffee contains active compounds that alleged to have antifungal activity. This study aimed to analyze inhibitory effect of steeping freeze-dried Robusta ground coffee (SFDRGC) to the growth of oral microorganism Candida albicans (the main causative agent of oro-pharyngeal opportunistic infection). This is an in vitro experimental study using the post-test only control group design. Serial dilutions of SFDRGC were studied. An antifungal drug Nystatin was used as a positive control, and sterile distilled water as a negative control. The inhibitory effect was study by means of Agar well diffusion method. Result showed that SFDRGC demonstrated antifungal activity. The higher concentration of SFDRGC showed the higher antifungal activities significantly $(P<0.05)$. Concentration of $100 \%$ SFDRGC showed anti-candida activity as potent as Nystatin. In conclusion, $100 \%$ SFDRGC demonstrated a potent antifungal agent against $C$. albicans. This study suggested that coffee beverage might be used as anti-candida mouthwash to prevent the risk of oral opportunistic infection. Further studies, however are needed to confirm this notion, such as epidemiological, and phytochemical studies of antifungal bioactive components in coffee that are processed using various methods.

Key words: Agar well diffusion method; antifungal; nystatin; opportunistic infection.

\section{INTRODUCTION}

Candida albicans is a commensal fungus normally found on oral mucous membrane in a healthy person, however, excessive growth of $C$. albicans could cause oral candidiasis. This oral microorganism was reported account for up to $95 \%$ of cases (Derhill; Iliyan, 2014; Villa et al., 2020). Oral candidiasis is one of the most common infectious diseases in the oral cavity. Oral candidiasis, commonly referred to as "thrush" is an opportunistic fungal infection (Villa et al., 2020). Oral candidiasis has largely been due to an increased incidence in condition of low host immunity, primarily because of the escalation in HIV-infection and the AIDS epidemic (Williams; Lewis, 2011). In addition, oral candidiasis was associated with the increased incidence of oro-pharyngeal cancer (Bakri et al., 2010; Sankari et al., 2015). Candidiasis causes some illnesses such as inconvenience, pain, and lost of appetite. In an acute condition, candidiasis can cause a burning sensation, pain on tongue, and xerostomia (Gurvits; Amy, 2013). To prevent candidiasis, therefore, the growth of this fungus must be controlled.

There are anti-fungal agents available, some study however reported that long-term administration of its drug might have detrimental side effects (Benitez; Carver, 2019; Levine; Chandrasekar, 2016). The used of herbal medicine supposed to serve an alternative method for controlling fungal growth. It is known to have a minimal side effect, relative cheap, and can be easily found in nature. One of the natural agents that is assumed to be useful for controlling the growth of $C$. albicans is coffee.

Coffee bean and the side product contains some bioactive substances such as caffeine, phenols, flavonoids, alkaloids, and saponins (Acevedo et al., 2013; Damat et al., 2019; Heeger et al., 2017; Rodrigues; Bragagnol, 2013) which can inhibit the growth of fungi. Caffeine have been reported inhibit the synthesis of fungi's plasma membrane and cause the lyses of the fungi (Gonzalez-Lamothe et al., 2009). Phenols substances can interact with fungi's membrane protein and cause structural and functional changes (Pusztahelyi; Imre; Isthvan, 2015). Flavonoids interferences the formation of pseudo-hypha of the fungi (Morais-Braga et al., 2017). Alkaloids have a role in inhibiting DNA synthesis of the fungi (Dhamgaye et al., 2014).

This study concern with Robusta coffee [Coffea canephora (Pierre ex A. Froehner)] for the reasons is that Robusta coffee supposed to have active antifungal substances stronger than Arabica coffee. Robusta coffee contained higher caffeine and flavonoids (Patay; Bencsik; Papp, 2016). Some factors might influence the medicinal effect of coffee such as variety of coffee, grind size and brewing methods (Fuller; Rao, 2017). Coffee is usually consumed after steeping in hot water. This study analyzed freeze-dried Robusta ground coffee (FDRGC), this method provide more fine grind size and a highly soluble in water, and therefore provide more homogenous solution than the regular ground coffee. In addition, the strength of antifungal activity was dose-dependent. The purpose of this study was to analyze the inhibitory effect of 
several concentration of steeping freeze-dried Robusta ground coffee (SFDRGC) against the growth of $C$. albicans and define the effective concentration to inhibit its growth.

\section{MATERIAL AND METHODS}

\subsection{Materials}

Robusta ground coffee was the regular commercial pure ground coffee produced by State Coffee Plantation PTPN XII, Jember, Indonesia. Wild type of C. albicans (isolated from human oral cavity) was purchased from Department Microbiology Faculty of Medicine Universitas Brawijaya, Indonesia. The medium of $C$. albicans, Sabouraud Dextrose Agar (SDA), Saboroud Dextrose Broth (SDB) were purchased from Merck (Germany), and Nystatin (Cazetin Nystatin Drop) from Power Merchant.

\subsection{Preparation SFDRGC}

A total of $50 \mathrm{~g}$ regular Robusta ground coffee was pour into $500 \mathrm{~mL}$ of boiled distilled water, then stirred for $3 \mathrm{~min}$ and allowed to stand for $15 \mathrm{~min}$ at room temperature and filtered (100 mesh). The filtrate $\left( \pm 400 \mathrm{~mL}\right.$ was then frozen to about $-40^{\circ} \mathrm{C}$. This process resulted $\pm 10.5 \mathrm{~g}$ freeze-dried Robusta ground coffee (FDRGC). The SFDRGC was prepared by brewing $3 \mathrm{~g}$ FDRGC into $3 \mathrm{~mL}$ distilled water, and this was considered to be a $100 \%$ $\left(\mathrm{g} \mathrm{mL}^{-1}\right.$ ) concentration of SFDRGC. Serial dilutions were then made from this $100 \%$ concentration to $25 \%, 50 \%$ and $75 \%$.

\subsection{Preparation of C. allbicans}

Step (i). The solution of SDB was prepared by mixing $3.7 \mathrm{~g}$ SDB in $100 \mathrm{~mL}$ sterile distilled water, stirred and boiled and sterilized in autoclave $121^{\circ} \mathrm{C}$ for $15 \mathrm{~min}$, and incubated for $24 \mathrm{~h}$. The sterile SDB media will remain clear after $24 \mathrm{~h}$ incubation. Step (ii). Prepation of C. albicans suspension. As much as one ose $C$. albicans was inoculated into $2 \mathrm{~mL} \mathrm{SDB}$ (in test tube) and incubated at $37^{\circ} \mathrm{C}$ for $24 \mathrm{~h}$. The growth of C. albicans was indicated by increasing media turbidity. This C. albicans suspension was then stirred using thermolyne and the concentration was adjusted to $0.5 \mathrm{Mc}$ Farland standard. Step (iii). Preparation of SDA medium, a total 10.4 g SDA was mixed with $200 \mathrm{~mL}$ distilled water in Erlenmeyer, then stirred, boiled, and incubated $121{ }^{\circ} \mathrm{C}$ for $15 \mathrm{~min}$. Step (iv). Inoculation of $C$. albicans in SDA plate. SDA medium (warm temperature) was poured into eight sterile plate $(150-\mathrm{mm}$ petri dish glass), $25 \mathrm{~mL} /$ plate (the thickness was about $6 \mathrm{~mm}$ ). Then $0.5 \mathrm{~mL}$ C. albicans suspension was distributed and inoculated in the SDA plate and allow to stand (around $15 \mathrm{~min}$ ) to get agar phase medium (modification method by Bhavan et al., 2010).

\subsection{Analytical procedure}

This is an experimental in vitro study using the post-test only control group design. Anti fungal activity was studied using Agar well-diffusion method (modified method by Dahiya; Purkayastha, 2012). Briefly, in eight petri dish (contained C. albicans in SDA media), a total of six wells (Ø $5 \mathrm{~mm}$ ) were made in each petri dish. As much as $20 \mu \mathrm{L}$ sample were placed in each well. Well 1 to well 4 were placed for SFDRGC concentration $25 \%, 50 \%, 75 \%$, $100 \%$, respectively, well 5 for positive control (Nystatin), well 6 for negative control (distillated water). All petri dish were then incubated at $37{ }^{\circ} \mathrm{C}$ for $24 \mathrm{~h}$. Antifungal activity was demonstrated by inhibitory zone (clear zone) around wells, the diameter was then measured using a digital calliper.

\subsection{Data analysis}

The statistical analysis was performed using the SPSS Statistics 17 . The analysis was preceded by homogeneity and normality tests that used the Kolmogorov-Smirnov and the Levene tests. The data analysis was then carried out by Kruskal-Wallis test followed by a Mann-Whitney test.

\section{RESULTS}

Result showed that all SFDRGC groups demonstrated inhibition activity against the growth of $C$. albicans. It was confirmed statistically $(P<0.05)$ compared to negative control group (treated by distilled water). The higher concentration of SFDRGC showed significantly $(P<0.05)$ the higher antifungal activities. Treatment with SFDRGC $100 \%$ showed no significant difference $(P>0.05)$ with the positive control (Nystatin) group. This suggest that the 100\% SFDRGC inhibit the growth of $C$. albicans as potent as Nystatin. The measurements $(\mathrm{mm})$ of inhibition zona diameter are presented in Table 1. The description of inhibition zone was depicted in Figure 1 and Figure 2.

Table 1: Inhibition activity of Steeping Freeze-dried Robusta ground coffee (SFDRGC) against Candida albicans growth.

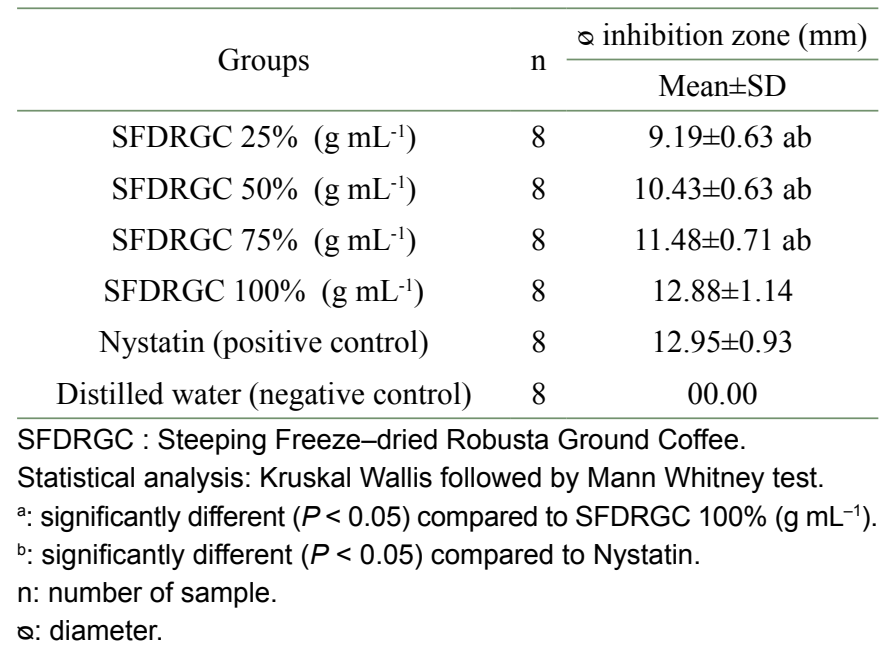




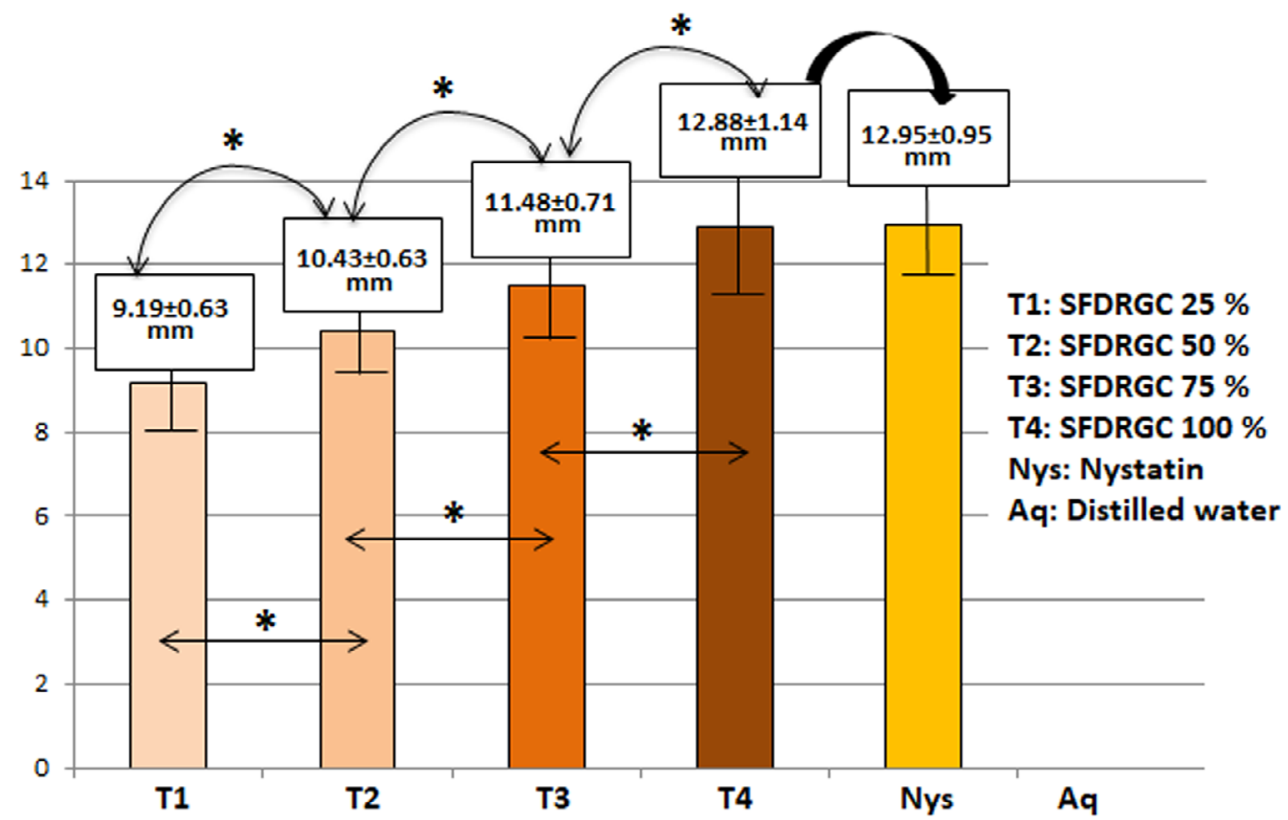

Figure 1: The inhibition activity of Steeping Freeze-dried Robusta Ground Coffee (SFDRGC, $\mathrm{g} \mathrm{mL}^{-1}$ ) against $C$. albicans was significant different between groups $(P<0.05)$.
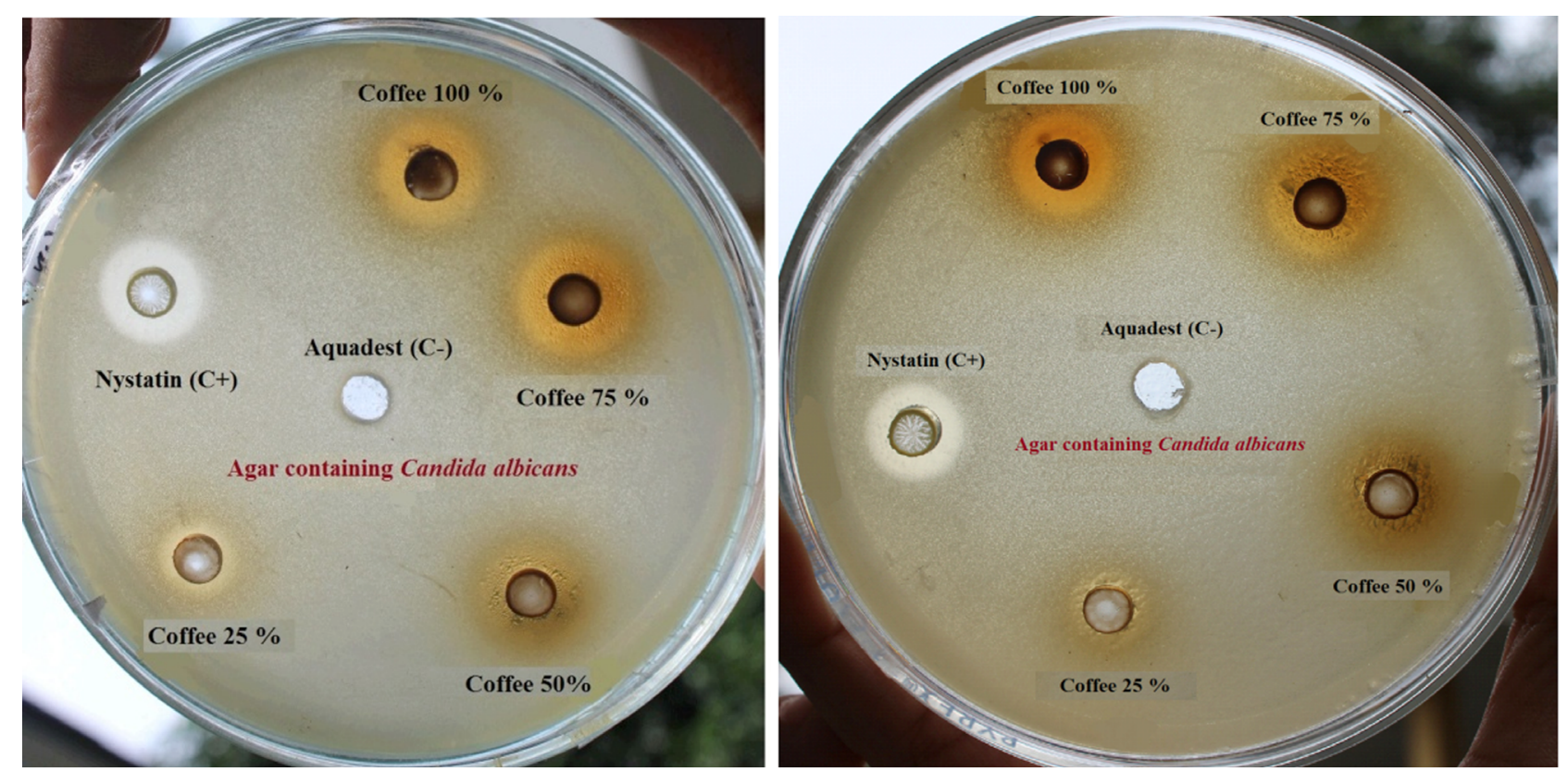

Figure 2: The antifungal activity of Steeping Freeze-dried Robusta Ground Coffee (SFDRGC) against Candida albicans demonstrated by Agar disk diffusion method. Anti C. albicans activity demonstrated by inhibition zone (clear area) surrounding wells. Agar wells (containing C. Albicans) were treated with 25\%,50\%, 75\%, 100\% SFDRGC (g mL ${ }^{-1}$ ) respectively. Well C(negative control, added by steril distilled water), and $\mathrm{C}+$ (positive control) treated by Nystatin.

\section{DISCUSSION}

Candida albicans is a commensal fungus normally found on oral mucous membrane in a healthy person This fungus makes up $40 \%$ to $60 \%$ of the population of the oral microorganisms (Benz et al., 2015). In certain condition, C. albicans can change to pathogenic, and infect human tissue leading to produce oral candidiasis. Candidiasis is caused by an overgrowth of $C$. albicans in the oral cavity (Singh et al., 2014).

Like others pathogenic fungi, C. albicans is a major causative agent for opportunistic infections (OIs). It becomes pathogenic under low host immunity. AIDS patients and other immunocompromised individuals are at risk for OIs, which if 
not treated appropriately, contribute to the mortality associated with their conditions. Several studies have indicated that the majority of HIV-positive patients contract fungal infections throughout the course of their disease (Mazu et al., 2016).

Some studies have reported antifungal drug resistance of C. albicans (Angiolella et al., 2008; Morschhäuser, 2016; Niimi; Firth; Cannon, 2010). Together these have suggested a need for developing new treatment options for OIs. To aid this effort, this study proposed the use of coffee for inhibiting the growth of C. albicans, in order to reduce OIs.

The antifungal activity of coffee is presumed because it contains compounds such as: caffeine, phenols, flavonoids, alkaloids and saponins (Jeszka-Skowron; Zgoła-Grześkowiak; Grześkowiak, 2015; Nasrollahi; Yadegari, 2016). Meanwhile, caffeine, phenols and flavonoids are higher in Robusta coffee than Arabica coffee (Jeszka-Skowron et al., 2016; Sousa et al., 2015). Based on the presumption the higher antifungal bioactive compounds, Robusta coffee became the focus of this study.

The content of active compounds from medicinal plants has a variety of mechanisms in inhibiting of the microorganism growth. Caffeine is a compound that inhibits the synthesis of cell walls resulting in the cell lysis and cause cell death (GonzalezLamothe et al., 2009). Caffeine is also a powerful antioxidant. In a study in vivo of caffeine acted as imunomodulator which served as the intrinsic chemical defense against insects, fungi and bacteria (Senchina et al., 2014). Caffeine is an alkaloid that makes coffee valuable to humans. Alkaloids are a class of natural compounds including nitrogen with properties of an organic amine base. The phenolic compounds have the ability to interact with membrane proteins that lead to changes in functional and structure of C. albicans (Dangi; Soni; Namdeo, 2010). Other study reported that caffeine was fungicidal against $C$. albicans. The date also suggests that the antifungal action of caffeine was enhanced by antifungal drug. Studies of the antifungal activity of caffeine against Saccharomyces cerevisiae showed results similar to those against $C$. albicans (Nasrollahi; Yadegari, 2016). Reinke et al. (2006 in Nasrollahi; Yadegari, 2016) reported that the mechanism of the fungicidal effects of caffeine involved causing damage to the cytoplasmic membrane of budding yeasts. Caffeine and its derivatives, methylxanthines, are powerful inhibitor of cAMP-phosphodiesterases from mammals, plants, insects, bacteria and fungi. One of methylxanthine functions is thus established to modulate endogenous cAMP, which critically regulates fungal life, including morphogenesis, virulence, nutrient sensing and reproduction (Sugiyama et al., 2016). Flavonoids have proven ability as an antifungal. Flavonoids disrupted the formation of the pseudohyphae of $C$. albicans during the pathogenesis (Serpa et al., 2012). Flavonoids often inhibit fungal growth with various underlying mechanisms, including plasma membrane disruption, the induction of mitochondrial dysfunction, and inhibiting the following: cell wall formation, cell division, RNA and protein synthesis, and the efflux mediated pumping system (Aboody; Mickymaray, 2020). Alkaloids disrupt the peptidoglycan components so the cell wall layers of yeast incomplete that it causes cell death. As for saponins influenced the permeability of the yeast cell membrane because it forms a complex with protein causing the destruction of the cell wall and cytoplasmic membrane. This effect was similar to natural polyphenol curcumin (CUR), that was shown cause fungicidal effect to $C$. albicans. CUR treatment induces reactive oxygen species (ROS) generation and cause early apoptosis in C. albicans cells (Dhamgaye et al., 2014).

In the present study, $100 \%$ SFDRGC was proven to show antifungal effect as potent as antifungal drug Nystatin. Freeze-dried processing seems to determine its antifungal effect. Our preliminary study using steeping of regular ground coffee demonstrated no antifungal activity against $C$. albicans. Freeze-dried method provided more fine grind size and therefore might provide higher soluble antifungal substances.

Considering SFDRGC as a potent antifungal agent, it is interesting and inspiring to study SFDRGC as a mouthwash for preventing opportunistic infection. To confirm the effect on the prevention of opportunistic infection, it is important to study SFDRGC role on inflammatory immune response against C. albicans. Previously, Dewanti et al., (2019) have shown that steeping of Robusta ground coffee could reduce inflammation against oral microorganism Streptococcus mutans. In addition, clinical trials and epidemiological studies were needed to study further. Its effect on others oral microorganisms were needed to study as well, since opportunistic infection usually is caused by collective microorganisms (fungi and bacteria). In the context of coffee, several factors might affect the fungicidal efficacy of coffee such as variety, quality, dosage, processing, brewing, etc., which served a wide area to study.

\section{CONCLUSIONS}

This study had proven that steeping freeze-dried Robusta ground coffee demonstrated a potent antifungal agent against $C$. albicans. It suggested that coffee beverage might be used as anti-candida mouthwash to prevent the risk of oral opportunistic infection. Further studies, however are needed to confirm this notion, such as immunological and phytochemical studies of antifungal bioactive components in coffee that are processed using various methods.

\section{REFERENCES}

ABOODY, M. S. A.; MICKYMARAY, S. Anti-fungal efficacy and mechanisms of flavonoids. Journals Antibiotics, 9(2):2-42, 2020. 
ANGIOLELLA, L. et al. Increase of virulence and its phenotypic traits in drug-resistant strains of Candida albicans. Antimicrobial Agents and Chemotherapy, 52(3):927-936, 2008.

ACEVEDO, F. et al. Spent coffee grounds as a renewable source of bioactive compounds. Journal of Biobased Materials and Bioenergy, 7(3):420-428, 2013

BAKRI, M. M. et al. Revisiting the association between candidal infection and carcinoma, particularly oral squamous cell carcinoma. Journal of Oral Microbiology, 2(1):248-271, 2010.

BENITEZ, L. L.; CARVER, P. L. Adverse effects associated with long-term administration of azole antifungal agents. Drugs, 79:833-853, 2019.

BENZ, M. V. et al. Growth of Candida albicans in human saliva is supported by low-molecular-mass compounds. FEMS Yeast Research, 15(8):1-8, 2015.

BHAVAN, P. S. et al. Culture and identification of Candida albicans from vaginal ulcer and separation of enolase on SDS-PAGE. International Journal of Biology, 2(1):8493, 2010.

DAHIYA, P.; PURKAYASTHA, S. Phytochemical screening and antimicrobial activity of some medicinal plants against multi-drug resistant bacteria from clinical isolates. Indian Journal of Pharmaceutical Sciences, 74(5):443450, 2012.

DAMAT, D. et al. Dietary fiber and antioxidant activity of gluten-free cookies with coffee cherry flour addition. Coffee Science, 14(4):493-500, 2019.

DANGI, Y. S.; SONI, M. L.; NAMDEO, K. P. Oral candidiasis: A review. International Journal of Pharmacy and Pharmaceutical Sciences, 2(4):36-41, 2010.

DERHILL, D. M.; ILIYAN, D. I. The mycobiota: Interactions between commensal fungi and the host immune system. Nature Reviews Immunology, 4(6):405-416, 2014.

DEWANTI, I. D. A. R. et al. The effect of steeping Robusta Coffee beans on monocytes: Expression of IL- $1 \beta$ and TNF- $\alpha$ against Streptococcus mutans. Coffee Science, 14(4):477-483, 2019.

DHAMGAYE, S. et al. Molecular mechanisms of action of herbal antifungal alkaloid berberine, in Candida albicans. PLoS One, 9(8):e104554, 2014.

FULLER, M.; RAO, N. Z. The effect of time, roasting temperature, and grind size on caffeine and chlorogenic acid concentrations in cold brew coffee. Scientific Reports, 7:17979, 2017.

GONZÁLEZ-LAMOTHE, R. Plant antimicrobial agents and their effects on plant and human pathogens. International Journal of Molecular Sciences, 10(8):3400-3419, 2009.

GURVITS, G. E.; AMY, T. Burning mouth syndrome. World Journal of Gastroenterology, 19(5):665-672, 2013.

HEEGER, A. et al. Bioactives of coffee cherry pulp and its utilisation for production of Cascara beverage. Food Chemistry, 221:969-975, 2017.

JESZKA-SKOWRON, M.; ZGOLA-GRZESKOWIAK, A.; GRZESKOWIAK, T. Analytical methods applied for the characterization and the determination of bioactive compounds in coffee. European Food Research and Technology, 240:19-31, 2015.

JESZKA-SKOWRON, M. et al. Chlorogenic acids, caffeine content and antioxidant properties of green coffee extracts: Influence of green coffee bean preparation. European Food Research and Technology, 242:14031409, 2016.

LEVINE, M. T.; CHANDRASEKAR, P. H. Adverse effects of voriconazole: Over a decade of use. Clinical Transplantation, 30(11):1377-1386, 2016.

MAZU, T. K. et al. The mechanistic targets of antifungal agents: An overview. Mini-Reviews in Medicinal Chemistry, 16(7):555-578, 2016.

MORAIS-BRAGA, M. F. B. et al. Phenolic composition and medicinal usage of Psidium guajava Linn: Antifungal activity or inhibition of virulence? Saudi Journal of Biological Sciences, 24(2):302-313, 2017.

MORSCHHÄUSER, J. The development of fluconazole resistance in Candida albicans-an example of microevolution of a fungal pathogen. Journal of Microbiology, 54(3):192-201, 2016.

NASROLLAHI, Z.; YADEGARI, M. H. Antifungal activity of caffeine in combination with fluconazole against Candida albicans. Infection, Epidemiology and Medicine, 2(2):18-21, 2016.

NIIMI, M.; FIRTH, N. A.; CANNON, R. D. Antifungal drug resistance of oral fungi. Odontology, 98(1):15-25, 2010.

PATAY, E. B.; BENCSIK, T.; PAPP, N. Phytochemical overview and medicinal importance of coffea species from the past until now. Asian Pacific Journal of Tropical Medicine, 9(12):1127-1135, 2016. 
PUSZTAHELYI, T.; IMRE, J. H.; ISTVÁN, P. Secondary metabolites in fungus-plant interactions. Frontiers in Plant Science, 6:573, 2015.

RODRIGUES, N. P.; BRAGAGNOL, N. Identification and quantification of bioactive compounds in coffee brews by HPLC-DAD-MSn. Journal of Food Composition and Analysis, 32(2):105-115, 2013

SANKARI, S. L. Candida in potentially malignant oral disorders. Journal of Pharmacy and Bioallied Sciences, 7(Suppl 1):162-164, 2015.

SENCHINA, D. S. et al. Alkaloids and athlete immune function: Caffeine, theophylline, gingerol, ephedrine, and their congeners. Exercise Immunology Review, 20(6):68-93, 2014.

SERPA, R. et al. In Vitro antifungal activity of the flavonoid baicalein against Candida species. Journal of Medical Microbiology, 61(12):1704-1708, 2012.
SINGH, A. et al. Oral candidiasis: An overview. Journal of Oral and Maxillofacial Pathology, 18(Suppl. 1):81-85, 2014.

SOUSA, C. et al. Coffee Industrial Waste as a Natural Source of Bioactive Compounds with Antibacterial and Antifungal Activities. In: MÉNDEZ-VILAS; A. (Ed.). The battle against microbial pathogens: Basic science, technological advances and educational programs. $1^{\text {st }}$ ed. Spain: Formatex Research Center, p.131-136, 2015.

SUGIYAMA, A. et al. Caffeine fostering of mycoparasitic fungi against phytopathogens. Plant Signaling \& Behavior, 11(1):e1113362, 2016.

VILA, T. et al. Oral candidiasis: A disease of opportunity. Journal of Fungi, 6(1):e15, 2020.

WILLIAMS, D.; LEWIS, M. Pathogenesis and treatment of oral candidosis. Journal of Oral Microbiology, 3(5771):1-11, 2011. 